\title{
Secondary Science Preservice Teachers' Perceptions of Engineering: A Learner Analysis
}

\author{
Trina J. Kilty ${ }^{1, *(1)}$ and Andrea C. Burrows ${ }^{2}$ \\ 1 School of Counseling, Leadership, Advocacy, \& Design, University of Wyoming, 1000 E. University Ave., \\ Laramie, WY 82071, USA \\ 2 School of Teacher Education, University of Wyoming, 1000 E University Ave, Laramie, WY 82071, USA; \\ Andrea.Burrows@uwyo.edu \\ * Correspondence: tkilty@uwyo.edu
}

Received: 30 November 2018; Accepted: 24 January 2019; Published: 29 January 2019

\begin{abstract}
The purpose of this study was to describe how US secondary science preservice teachers, or those preparing to teach middle and high school science, at one university, perceive engineering and teaching engineering within an epistemological framework of required domain components pre- and post-instruction (intervention) as well as over three cohort years. Their perceptions reveal relevant prior beliefs helpful for designing instruction to address an external need to prepare secondary science teachers to teach disciplinary content ideas, cross-cutting concepts, and science and engineering practices to meet the Next Generation Science Standards. Questionnaires administered pre- and post-instruction (intervention), as well as over three years, asked participants to decide whether various scenarios qualified as engineering and then to provide reasoning. Intervention instruction included whole-class discussions of engineering design practices. The responses to the questionnaire were analyzed for thematic content. The results indicate that the secondary science preservice teachers $(n=43)$ have a novice understanding of engineering and teaching engineering. They gain an emerging understanding during the secondary science methods courses, consistent in all three years with expanding perspectives from narrow discipline views. As their perceptions are refined, however, there are risks of oversimplification, which may lead to forming misconceptions. The recommendations for designing instruction such as secondary science methods courses and early career professional development include creating opportunities for preservice and early career teachers to explore and challenge their perceptions of engineering design practices integrated within science and engineering practices.
\end{abstract}

Keywords: engineering education; preservice teacher beliefs; perceptions; secondary science; NGSS; learner analysis; $\mathrm{K}-12$ teachers

\section{Introduction}

Science teaching in United States (US) K-12 schools is undergoing a change. With many states adopting the Next Generation Science Standards (NGSS) [1], most science teachers need to teach science and engineering practices (SEP) as well as cross-cutting concepts, in addition to disciplinary core ideas and concepts [1]. This change represents an innovation, something that is new to science teachers [2]. Science teachers should incorporate engineering design practices as the NGSS are implemented. Engineering design, however, differs from science inquiry practices [3]. A working definition of engineering design practices (EDP) has been described as "(a) defining and delimiting engineering problems; (b) designing solutions to engineering problems; and (c) optimizing the design solution" [1] (p. A2). EDP differs from SEP in that SEP typically investigates a natural phenomenon, while EDP focuses on designing and building systems [1]. The two share a teaching goal of hands-on 
practices to deepen and apply knowledge of scientific principles. In order to design and develop instruction for secondary science preservice teachers to prepare them to teach incorporating the NGSS in their science classrooms, it is important for researchers to describe what perceptions are held toward engineering. In this study, preservice teachers are students seeking teaching certification, and some have obtained previous science, technology, engineering, and mathematics (STEM) degrees. The innovation in this study is defined as the use of the NGSS, SEP section, which asks teachers to integrate EDP with science when planning, implementing, and assessing student learning. Implementation of the NGSS establishes an external need for instruction regarding teaching engineering [4]. An innovation may provide a need to design instruction [5]. Instruction may provide learners logical and compelling reasons to adopt the innovation [2]. Understanding learners, or learner analysis, is the first step towards designing instruction to address the innovation [5]. The participants in this study are the subject of the learner analysis and, for clarity, will be referred to as participants or secondary science preservice teachers rather than learners. The participants in this study are defined as three secondary science preservice teacher cohort groups from 2015-2017 $(n=43)$. Instruction in this study is defined as coursework, including secondary science teaching methods and professional development, that encompasses a variety of learning strategies and learner-centered activities. Secondary science teaching methods are two courses that are considered capstone courses, along with student teaching residency, before gaining teaching certification. The learner context setting is secondary science methods courses implemented at a research university in the Rocky Mountains of the US. Figure 1 showcases how this study fits within an instructional design innovation model.

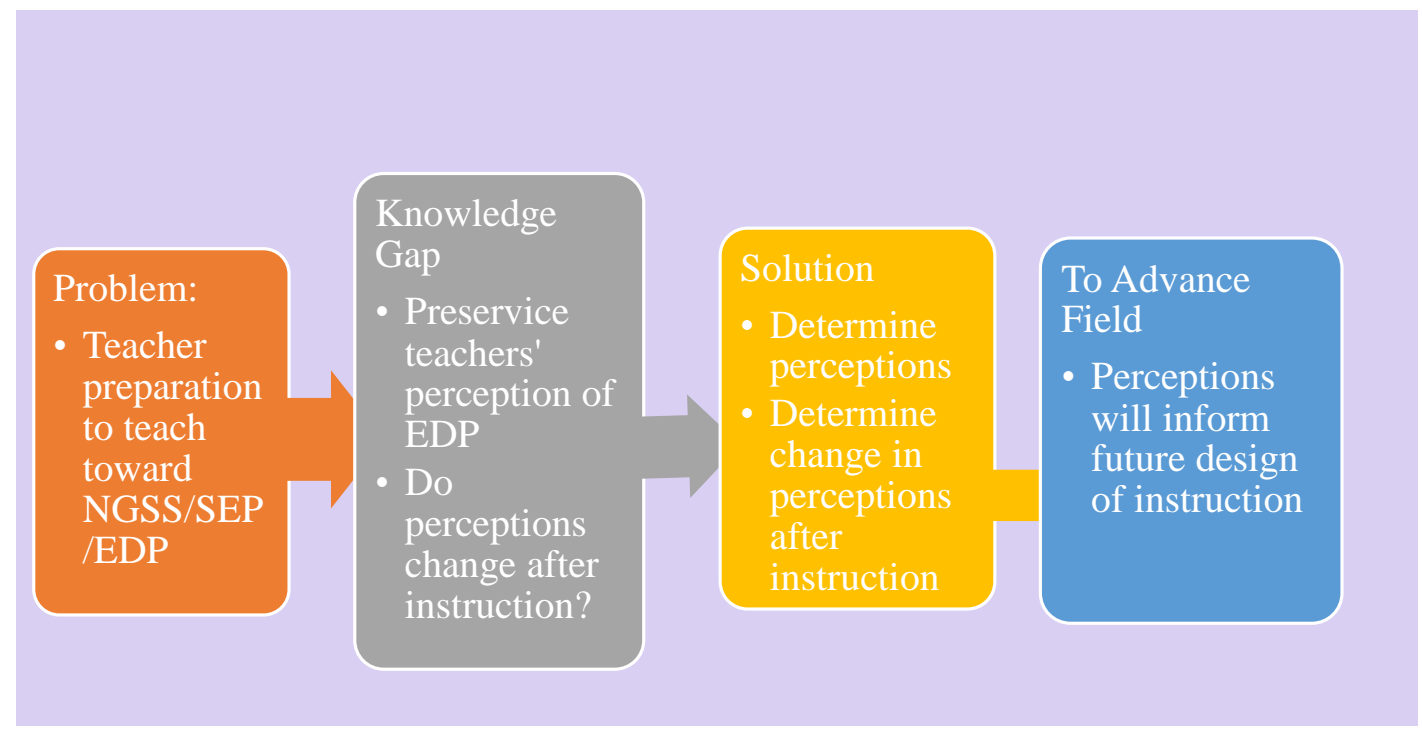

Figure 1. Overview of this study from statement of the problem and knowledge gap to the solution and advancement of the education field.

The purpose of this study was to describe how US secondary science preservice teachers, or those about to be certified to teach middle and high school science, at one university, perceive engineering and teaching engineering within an epistemological framework of required domain components pre- and post-instruction (intervention) as well as over three cohort years. An instructional design framework was used to place this study in terms of learner analysis and need for instruction [5]. This study describes perceptions, based on prior knowledge and beliefs that are refined after instruction, that are useful for designing instruction including methods courses and early in-service professional development for teachers. 


\subsection{Background}

Like engineering, instructional design ideally begins with a problem that may be solved. In this case, the problem is how to effectively prepare secondary science preservice teachers to teach EDP. Instructional designers try to solve the problem by developing instruction to fill a gap in knowledge. One of the first steps in designing instruction is to know the audience, in other words, the characteristics of the learners within their context. Learner characteristics may be classified by similarities and differences in participants and whether those similarities and differences are stable or change over time [5]. Values, beliefs, motivations, and interests are considered to be changing differences among participants, influenced and shaped by experiences [5]. Perceptions toward engineering and toward teaching engineering may fit best into a changing difference, as perceptions are influenced by experience in life and in coursework. Secondary science preservice teachers craft these perceptions into a belief about what engineering is and how it is defined. This may be considered an epistemological belief about a disciplinary field and what knowledge that field encompasses. Their beliefs may exert some influence on how they will teach EDP. Figure 2 displays the study situated in an instructional design problem and solution.

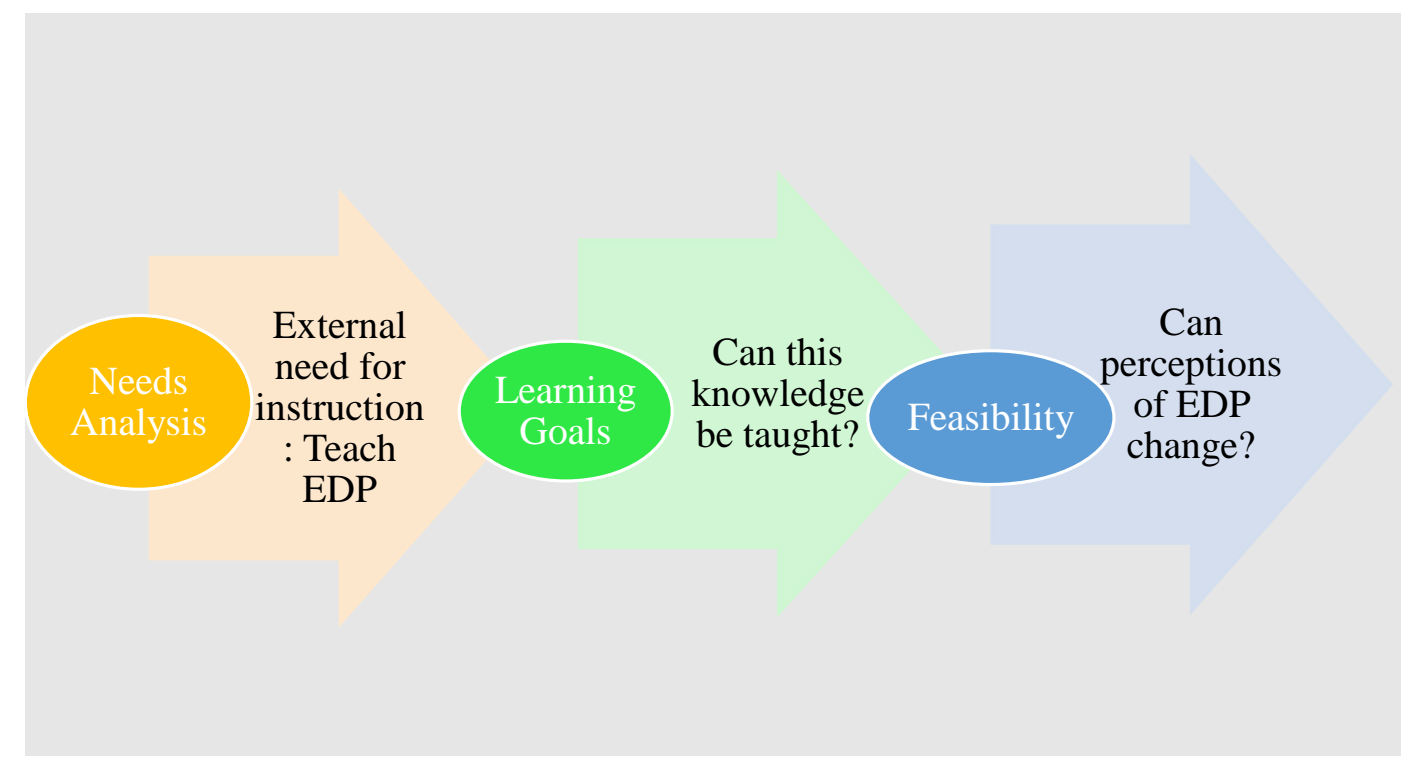

Figure 2. Innovation needs analysis model and the situation of this study within it [5].

The EDP domain and teaching engineering may be something secondary science preservice teachers never thought they would need to teach. However, the context of engineering education can be traced back to Science for All Americans: Project 2061, which explained the importance of a scientifically literate population able to make informed decisions based on familiarity with science and engineering practices [6]. The NGSS formally combined science with engineering into the SEP [1]. STEM communities are writing engineering and computer science standards in several states with implementation to follow shortly [1]. Because of these standards, it is important for preservice science teachers to prepare to incorporate engineering instruction and raise awareness of engineering career opportunities, which can also include computer science instruction.

Research communities have debated whether to incorporate standalone engineering standards for K-12 or to integrate engineering into science standards. Prior to the NGSS, several states included EDP in their science curriculum [7]. Some researchers proposed a framework for including standalone engineering courses that complemented a firm foundation in math and science [8], but others proposed a framework in which engineering was integrated into existing STEM courses [9]. Some have criticized the NGSS as only including EDP in the standards, not providing a complete picture of the engineering domain or focusing on the nature of engineering [10]. The NGSS do not include 
engineering disciplinary core ideas in the standards, but rather focus on integrating EDP into SEP. Integrated STEM classes should align with the NGSS, as the SEP portion of the NGSS combines science and engineering as one integrated process [1]. Although adoption of the NGSS and its integrated curriculum may settle the matter in some states, not all states have adopted the standards, or a variation of the standards [11]. Researchers have recommended the integration of engineering with other STEM disciplines in teacher training, primarily because teachers "differed widely on what they considered engineering to be" and "how they implemented engineering concepts" [12] (p. 9). One plan for science teacher preparation is to focus on the integration of engineering within existing STEM classes, especially science and technology, as opposed to planning to teach standalone engineering courses [13]. This plan allows preservice teachers to gain familiarity with the NGSS science and engineering integration framework as they prepare to begin teaching.

Thus, professional development for in-service teachers is important and needed to teach the NGSS integration skills. Throughout the US, professional development (PD) opportunities at all teaching career levels have been offered to facilitate implementation of the NGSS (i.e., encourage adoption of the innovation) and prepare teachers to teach EDP. Although the purpose of many professional developments is the adoption of an innovation, actual behavior change-changing practices in the classroom-must occur, and this is not always the case [14]. Professional development (PD) in teaching engineering for in-service teachers often includes instruction on fundamental content knowledge, essential pedagogical principles, and challenges for implementation [15]. The focus on content may come at the expense of emphasizing process and at the expense of developing strategies for adopting an innovation. Interpersonal skills, pedagogical applications of engineering, and reflective discussion have historically been rare activities in engineering professional development [15]. In recent years, however, progress has been made towards incorporating these activities [16-18]. These activities may be incorporated into secondary science methods courses to help secondary science preservice teachers socially construct their beliefs with peer support before entering their first classroom to teach. A preemptive approach of addressing the innovation earlier, such as in secondary science methods courses, may help adoption by refining perceptions before teachers begin teaching.

\subsubsection{Epistemology of Engineering Design Practices}

Secondary science preservice teachers' beliefs about engineering and teaching engineering are part of an overarching epistemological belief about knowledge and knowing about engineering as a discipline and how it relates to other disciplines. Epistemological knowledge of a domain such as engineering may encompass beliefs, perceptions, and ways of knowing to shape understanding [19]. Domain knowledge consists of declarative, procedural, and conditional knowing [19]. The researchers of this study asked participants to use procedural knowledge of the engineering domain to determine if a given scenario fits into an engineering domain and to explain their reasoning. Procedural knowledge is an intellectual skill learned in part through the spread of activation such as reminding the participant of prior knowledge, prior experience, or of acquaintances [20]. The spread of activation may cause secondary science preservice teachers to relate EDP to a science content domain with which they are more familiar.

Secondary science preservice teachers' prior experiences and domain knowledge in other content areas may influence their epistemological beliefs and practice regarding EDP. In one study, in-service teachers who began teaching after a career in science attached importance to aspects of science that were valued at their previous careers [21]. For example, a former lab technician prioritized precision in data collection, analysis, and interpretation during classroom activities. Ways of knowing about a knowledge domain, namely engineering, may relate to one's domains of expertise, or major content area, but precisely how epistemological knowledge of a familiar domain influences beliefs of a less familiar domain has not been explored in detail [19]. Data analysis, for example, is one area where prior knowledge in a science domain may affect reasoning [22]. Content domain knowledge in a science or mathematics discipline influences how a person interprets evidence [22]. Further research is needed 
to explore post-baccalaureate preservice teacher perceptions of teaching science and engineering in the classroom [21]. The authors believe that the participants of this study, because more than half in each cohort year were post-baccalaureates, present a sample that are in keeping with the research recommendations of Antink-Meyer and Brown [21]. Perceptions regarding data analysis represent another avenue deserving of study.

Knowledge of EDP as a domain is a prerequisite skill needed for lower, novice stages of learning before the expert (mastery) stage [20]. In this study, demonstration of novice to expert learning may be the recognition of different facets of the EDP domain by reasoning through examples and nonexamples. One characteristic of expert, as opposed to novice, is that knowledge is "the recognition of meaningful patterns of information ... organized around core concepts" [23] (p. 36). Researchers characterize experts as having an "elaborateness of understandings" while novices may use recall to reason through a problem requiring knowledge domain [23] (p. 41). Instruction during a college course may facilitate progress toward mastery by helping preservice teachers organize their knowledge in meaningful patterns and apply general components of engineering to specific teaching and learning scenarios they will encounter during teaching.

The path to expert knowledge, however, is full of pitfalls. There is a danger that preservice teachers may develop misconceptions about EDP and teaching engineering and bring the misconceptions into the classroom. Four misconceptions held by teachers about engineering were identified in a previous study: (a) research methods in engineering are defined by long-term implications or outcomes, (b) science and engineering is hierarchal, (c) creativity is appropriate only in the design/planning phase, and (d) an engineering process cannot be a research outcome [24]. Because preservice teachers may not have prior coursework in engineering and may be unfamiliar with engineering, they may already hold or may develop a number of misconceptions about epistemology of engineering, such as the four previously mentioned here. In keeping with identified areas of need in the literature, Jones and Carter [25] specifically call for research studies that address individuals' patterns of reasoning that differ across content domains.

\subsubsection{Instruments to Measure Perceptions}

Advances have been made to address the knowledge gap of epistemological beliefs toward engineering. An instrument, entitled Conceptions of Teaching Engineering, was developed from the Conceptions of Teaching Science task [26,27]. Researchers interviewed in-service teachers and identified initial conceptions of the required components of engineering and teaching engineering [27]. Researchers prepared a list of engineering components to include (a) applications to the real-world; (b) creating or designing a model or product; (c) experimentation and gathering data; (d) conducting background research; (e) revising or optimizing the solution; (f) confronting a challenging, multi-step problem with multiple possible solutions; $(\mathrm{g})$ brainstorming; and (h) communication within the team and to a wider audience [27]. The study explained in this article extends and builds on that work by determining if the identified engineering components replicate in a different group of participants.

Researchers have completed work exploring beliefs and conceptions that teachers hold about engineering. The Design, Engineering, and Technology (DET) instrument asks about items along many constructs, including (a) perceptions of familiarity, self-efficacy, motivation and desire to teach DET; (b) perceived importance of DET to the curriculum and barriers to teaching; (c) perceptions of a typical engineer; and (d) personal characteristics best suited for engineering [28]. The DET instrument was administered to elementary preservice teachers pre- and post-short-course on engineering design [29]. The preservice teachers gained a novice level of procedural knowledge [30]. The researchers in this study did not use the DET instrument because the constructs did not specifically address perceptions of what EDP is and is not.

Teachers need to effectively communicate to their students what a career in engineering entails, and this requires that they form a comprehensive understanding of the engineering field. In a prior study, an instrument was developed to measure in-service teachers' beliefs about students' aptitude 
for a career in engineering [31]. Although findings revealed teachers placed importance on attributes such as high GPA and advanced math skills, it was not determined what teachers thought was fundamentally required to classify activities as engineering. The recommendations to address this gap included raising awareness among teachers about what engineering is and what engineers do [32]. The aforementioned study focused on in-service teachers; and currently preservice teachers' views are poorly understood.

Other instruments have been developed to approach the problem from different angles. Researchers have asked elementary and middle school students to explain their perceptions of engineering and technology in an instrument containing pictures and images as well as open-ended questions about engineering and technology as defined by the participant [33,34]. While a comparison of perceptions from teacher and student perspectives is outside the scope of this study, it further illustrates the gap in the literature about secondary science preservice teachers' perspectives.

This study examined the domain perceptions that participants held outside of their major focus of study. Examining secondary science preservice teachers' beliefs about engineering partially addresses a recommendation from other researchers that future research determine "epistemological assumptions and patterns of reasoning [that] may differ for individuals across content domains" [25] (Future Research, para. 1). On the basis of this recommendation, the authors of this study identified a gap in the literature regarding how prior knowledge, or knowledge applied from other domains, may influence secondary science preservice teachers' beliefs and future classroom behaviors regarding engineering and teaching engineering. The participants in this study hold or are seeking degrees in science, mathematics, and education and their knowledge has been shaped by various previous knowledge, careers, and experiences.

Using the aforementioned literature gap in patterns of reasoning, this study begins to address previous researchers' recommendations by describing secondary science preservice teachers' perceptions of engineering and teaching engineering, many of whom hold degrees outside of the engineering domain. To probe the patterns of reasoning, the authors of this study administered a questionnaire to secondary science preservice teachers. The questionnaire items provided a framework for analyzing the participants' responses and formulating the research questions. The authors of this study administered the questionnaire over a period of three years to examine how perceptions may differ over time in different cohorts. Finally, this study placed perceptions of engineering into a need for instruction and learner analysis portion of an overall instructional design context. The questionnaire was administered both pre- and post-methods instruction to gauge if instruction was effective in changing perceptions and is therefore needed. To address Antink-Meyer and Brown's [21] and Jones and Carter's [25] recommendations, as well as determine if the findings of a previous study would replicate [27], the following research questions were created and examined:

1. How do secondary science preservice teachers describe their perceptions of engineering and teaching engineering within an epistemological framework of required domain components?

2. How do secondary science preservice teachers show changing understanding of engineering and teaching engineering from pre-instruction to post-instruction of secondary science methods course?

3. How do secondary science preservice teachers' perceptions of engineering and teaching engineering trend over three cohort years?

\section{Materials and Methods}

\subsection{Theoretical Framework and Methodology}

This study utilized qualitative research to answer the research questions. The framework is of an interpretivist, constructivism theoretical perspective [35]. This study used a subjectivist lens to describe individuals' beliefs and perspectives about a knowledge domain. The methods included the purposeful sampling of a homogeneous group of secondary science preservice teachers taking a capstone course 
entitled secondary science methods. Data were collected by open-ended written questionnaires and analyzed by textural analysis. The researcher's role was detached, as no conversations occurred while the participants completed the questionnaire. Participants produced the data individually on the questionnaire but had opportunities to discuss and plan for secondary science engineering lessons in the course. This study offers pragmatic validity [35], and readers might find pragmatic validity by determining if the results apply to other learners in other contexts. Learner analysis fits into a general instructional design paradigm termed ADDIE, which stands for Analysis, Design, Development, Implementation, and Evaluation. Instructional design models follow this overarching paradigm, illustrated in Figure 3 [36]. This study fits into the early stages (A, or analysis) of the instructional design process. Participants described perceptions relevant to their epistemology (learner analysis) and prior knowledge and beliefs (task analysis), which is based on experiences and conceptions regarding EDP and teaching engineering [5]. This study determined if a need for instruction existed for teaching engineering and if instruction was effective at changing participants' perceptions. By examining and decomposing prior knowledge and beliefs about EDP and teaching engineering, designers may analyze nuances and changes in understanding, which could focus and direct instruction more effectively [5]. The results from this study can help inform future steps of the instructional design process.

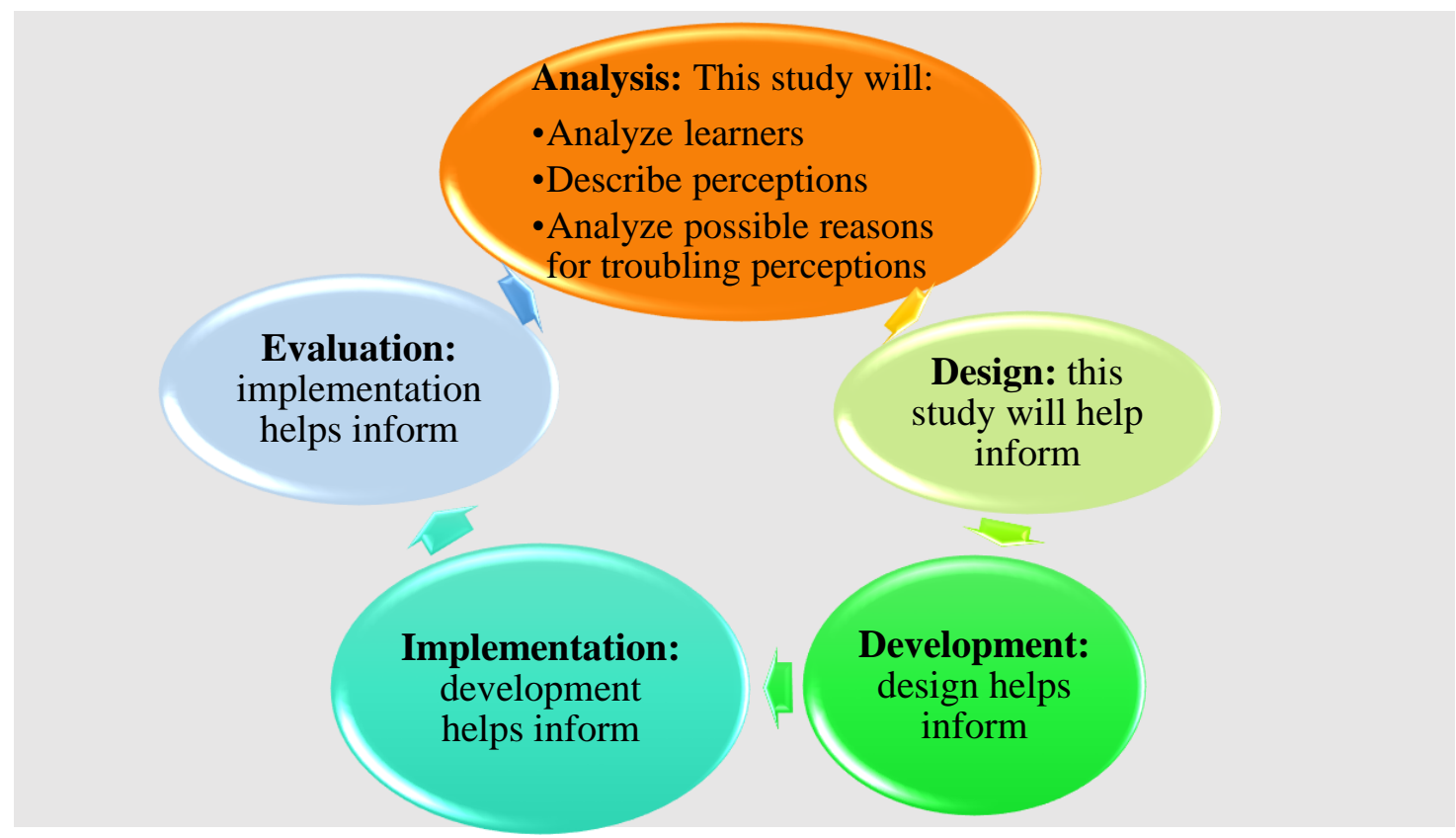

Figure 3. This study fits into the Analysis stage of the general instructional design Analysis, Design, Development, Implementation, and Evaluation (ADDIE) paradigm [36].

Within the general ADDIE paradigm lies an instructional design model to address an innovation and also one to design for motivation. This study fits into the initial stage of designing instruction, the Analysis stage [36]. This study helps inform design for motivation, which would focus on initial stages of relevance through describing prior knowledge and perceptions [20]. The findings gleaned during the analysis stage help inform the next stage of design, which in turn helps inform implementation and evaluation of the instruction, and analysis begins again after examining the evaluation. In this sense, instructional design is an iterative process of optimizing instruction and learning. The goal of informed design is for instruction to be effective. In this case, secondary science preservice teachers would adopt the innovation of teaching engineering design practices integrated with science practices. 


\subsection{Methods}

\subsubsection{Participants}

The participants were a cohort of secondary science preservice teachers in two secondary science methods courses grouped in academic years for 2015, 2016, and 2017 (three years total). Secondary science preservice teachers typically took secondary science methods courses the semester (fall) before they student taught (spring). After that, they graduated and secured science teaching certification and teaching positions. The two methods courses are a capstone for secondary science education. In this study, each year is considered a cohort where secondary science preservice teachers completed the engineering scenario questionnaire, henceforth referred to as the pre-test, at the beginning of the semester. The same cohort then completed the same engineering scenario questionnaire, henceforth referred to as the post-test, upon conclusion of the courses at the end of the fall semester. All of the participants completed two secondary science education methods courses. Therefore, two required secondary science methods courses, taken concurrently, functioned as the intervention. Table 1 displays the learner characteristics of the participants by cohort year. Not all of the experiences add up to the $n$ for each year because many participants held more than one degree conferred in different years, double-majored and/or pursued multiple minors, and/or both substitute-taught and tutored.

Table 1. Participant experiences, 2015-2017, by year.

\begin{tabular}{|c|c|c|c|c|c|c|c|}
\hline Year & $n$ & $\begin{array}{c}\text { Science } \\
\text { Degree(s) Held }\end{array}$ & $\begin{array}{c}\text { Science } \\
\text { Major(s) and } \\
\text { Minor(s) }\end{array}$ & $\begin{array}{l}\text { Years since } \\
\text { Degree } \\
\text { Conferred }\end{array}$ & $\begin{array}{c}\text { Teaching } \\
\text { and/or Tutoring } \\
\text { Experience }\end{array}$ & $\begin{array}{l}\text { Informal } \\
\text { Teaching } \\
\text { Experience }\end{array}$ & $\begin{array}{c}\text { Non-Teaching } \\
\text { Work } \\
\text { Experience }\end{array}$ \\
\hline 2017 & 11 & $\begin{array}{c}\text { None (4) } \\
\text { BS (7) } \\
\text { MS (1) }\end{array}$ & $\begin{array}{c}\text { Life Science (4) } \\
\text { Physical Sci. (3) } \\
\text { Earth Science (6) } \\
\text { Math (1) }\end{array}$ & $\begin{array}{l}\text { N/A (4) } \\
<5(6) \\
5-10(1)\end{array}$ & $\begin{array}{l}\text { None (4) } \\
\text { Substitute } \\
\text { Teaching (1) } \\
\text { Tutoring (6) }\end{array}$ & $\begin{array}{l}\text { Yes (9) } \\
\text { No (2) }\end{array}$ & $\begin{array}{l}\text { Yes (10) } \\
\text { No (1) }\end{array}$ \\
\hline 2016 & 15 & $\begin{array}{c}\text { None (5) } \\
\text { AS (1) } \\
\text { BS (11) }\end{array}$ & $\begin{array}{c}\text { Life Science (9) } \\
\text { Physical Sci. (4) } \\
\text { Earth Science (6) } \\
\text { Engineering (1) }\end{array}$ & $\begin{array}{l}\text { N/A (5) } \\
<5(7) \\
5-10(3)\end{array}$ & $\begin{array}{c}\text { None (8) } \\
\text { Substitute } \\
\text { teaching (2) } \\
\text { Tutoring (5) }\end{array}$ & $\begin{array}{l}\text { Yes (13) } \\
\text { No (2) }\end{array}$ & Yes (15) \\
\hline Total & 17 & $\begin{array}{c}\text { None (11) } \\
\text { AS (2) } \\
\text { BS (4) } \\
\text { MS (1) }\end{array}$ & $\begin{array}{c}\text { Life Science (15) } \\
\text { Physical Sci. (3) } \\
\text { Earth Science (4) } \\
\text { Math (1) }\end{array}$ & $\begin{array}{l}\text { N/A (11) } \\
<5(6)\end{array}$ & $\begin{array}{c}\text { None (9) } \\
\text { Substitute } \\
\text { Teaching (5) } \\
\text { Tutoring (3) }\end{array}$ & $\begin{array}{l}\text { Yes (14) } \\
\text { No (3) }\end{array}$ & $\begin{array}{l}\text { Yes (15) } \\
\text { No (2) }\end{array}$ \\
\hline
\end{tabular}

Overall, 43 secondary science preservice teachers participated in the study. The number of participants each year ranged from 11 to 17 . Of the participants, about $47 \%$ were undergraduates who would earn their first degree that next spring; $58 \%$ already held degrees ranging from associate degrees to master's degrees; and approximately $12 \%$ held two or more degrees. Science degrees, majors, minors, and endorsements were in the general areas of life sciences (65\%, typically biology), earth sciences ( $37 \%$, typically geology), and physical sciences ( $23 \%$, typically chemistry). The percentages do not add up to 100 because some participants listed more than one major, minor, and/or endorsement. Only one of the 43 total participants held a degree in engineering. Only two participants in different cohorts indicated a double major or minor in mathematics. All participants held a substitute teaching permit, as required by the program, but no one in the three years held a full teaching license with classroom teaching experience. This is not surprising, as the objective of the program is to earn a secondary science teaching certification. Only substitute teaching in K-12 environment was counted as teaching. Experience as an undergraduate teaching assistant at the university was counted as tutoring. For comparison purposes, participants were treated as a homogeneous group by cohort year.

\subsubsection{Instrumentation}

Data were collected by use of a questionnaire. The instrument, entitled Conceptions of Teaching Engineering (CTE), was developed from the Conceptions of Teaching Science (CTS) task [26,27]. Part 
two of the questionnaire included six questions inspired by the work that developed a task analysis for determining science and teaching science [26]. While likely inspired by a similar source, the authors of this study were unable to locate the original source of the items in part one. While the scenarios in part one could easily fit into a scientific domain, there was the possibility that participants would articulate differentiation criteria between what appeared to be science and with what they perceived to be engineering. Scenarios were modified to address engineering design practices [27]. Box 1 displays the items on the questionnaire and protocol.

Box 1. Modified Conceptions of Teaching Engineering (CTE) questionnaire [27].

Questionnaire Prompt: The purpose of these scenarios is to determine your thoughts on what makes an activity one where teaching engineering is taking place or not. There are two sets of scenarios that you will be asked to decide and explain whether or not you think that the scenario is an example of "teaching engineering". There are no right or wrong answers.

1. If you cannot tell (MAYBE) — What would you need to know if this is teaching engineering?

2. If YES-What tells you that this is an example of teaching engineering?

3. If NO-What tells you that this is NOT an example of teaching engineering?

\section{Scenario Descriptions: (Part One)}

1. Students in a 7 th grade mathematics class are working on graphing data. The teacher has student pairs measure their pulse each minute for 10 min while one student jogs in place.

2. Sixth grade science students are studying a unit on earthquakes. The teacher asks students to find the difference between two historical earthquakes using a table involving magnitudes according to the Richter scale.

3. A 4th grade class is doing a project on dinosaurs. A group of students makes a chart that compares the sizes of the five different dinosaurs showing their metric heights and weights.

4. Students are investigating ocean floor depths using data from sonar equipment. They are given the equation $\mathrm{D}=1 / 2 \mathrm{~T} \times \mathrm{V}$, where $\mathrm{D}=$ depth in $\mathrm{m}, \mathrm{T}=$ time in $\mathrm{s}, \mathrm{V}=$ the speed of sound in water $(1535 \mathrm{~m} / \mathrm{s})$. The students are then asked to compute ocean floor depths given the time required for sound to be sent and return to an echo sounder.

5. During a unit on the solar system, the teacher asks the students to create a scale model that shows the relative size and distance between the Earth and two other planets.

6. Eighth grade students are investigating crystal formation as the liquid in different solutions evaporates. Students are asked to observe and describe various characteristics of the crystals formed when the liquids evaporate.

\section{Scenario Descriptions: (Part Two)}

1. Two students working on slope y-intercept problems for homework from their textbook.

2. A student making fudge.

3. A student is home watching a documentary about building the Hoover Dam in the 1930s.

4. A 10th grade class creates rapid composting columns. The teacher puts out a challenge to the students to create a plan for a community rapid composting plant.

5. In an 11th grade physics class, the students use a rocket kit to build a compressed air rocket.

6. After an accident in the school parking lot, the teacher for an after school enrichment project decides the group should develop a traffic regulation system.

7. After learning about plate tectonics, an 8th grade science teacher has students create toothpick and marshmallow structures then tests their strength on a shake table.

8. A class reads an article about genetically modified foods, and then debates the pros and cons of using technology in food production.

9. A math teacher has students measure the water use by a dripping faucet in a 10 min interval, and then create a linear equation to represent the data.

10. A class trip to an amusement park.

11. Two kids adjust and test their BMX bike seat height to figure out how to get maximum speed going into a jump ramp.

The CTE previously described utilized an interview protocol, and the researchers in the former study verbally interviewed participants and transcribed the interviews [27]. In this study, the authors 
replaced the interviews with a pencil-and-paper questionnaire. The questions were typed, leaving space for participants to circle yes, no, or maybe as a response and then use additional space to explain or justify their answer. The questionnaires were printed, and the participants hand-wrote their answers. The questionnaires were distributed during class shortly after the class began. In some years, it was as early as the first day that the secondary science methods courses met. The post-tests were administered on the last day methods courses met. The study's authors secured the university's Institutional Review Board approval. Participants gave consent for the study on a separate form and created a unique code to ensure confidentiality.

The participants used procedural knowledge of EDP and teaching engineering to read through the scenario, decide whether the activity met their criteria to classify the scenario as an example of engineering or teaching engineering, and justify their reasoning. Answering the questions called for domain-specific if-then intellectual skills, either prior knowledge for the pre-test or after methods class instruction intervention for the post-test [20]. For example, for scenario 9 (measuring water in 10-min intervals and creating a linear equation of the data) participants needed to determine: if data collection was sufficient to label it engineering, then the answer was yes; if the activity gave no further details, then what additional activity was necessary to elevate it sufficient to be called engineering; and if the activity also required creating an equation, then that made it sufficient to label the activity part of the engineering domain.

\subsubsection{Intervention Description}

Secondary science methods courses served as the instruction intervention for this study. The participants at the university took two methods courses concurrently as part of their capstone instruction. The methods courses were designed to meet the US InTASC standards and Standards for Science Teacher Preparation to include content knowledge and related pedagogy, safety skills, assessment of student learning, learning environments, and professional knowledge and skills [37,38]. The courses included many activities that encouraged the thoughtful integration of SEP including developing and presenting demonstrations, creating and peer-critiquing videotaped micro-teach lessons, creating a professional portfolio of work (edTPA) that incorporated SEP into every lesson, and developing a unit plan that included SEP. The multiple assignments and projects that specify secondary science preservice teachers apply and use SEP are frequently utilized when the participants teach. For example, in the courses, secondary science preservice teachers created learning centers that addressed a misconception in their content area. Middle school students from a nearby school participated in the learning center activity and provided the secondary science preservice teachers authentic feedback for consideration when used in future K-12 science classrooms.

Regarding EDP specifically, instruction and activities varied by cohort year. In year 2015, secondary science preservice teachers completed an activity that used EDP using Lego Mindstorm Robotics [4]. During every cohort year, secondary science preservice teachers discussed their own and their future students' perceptions of engineering and teaching engineering as a large group. The science educator presented a slideshow that included a definition of engineering but did not provide a handout of the material. Secondary science preservice teachers were not required to create a separate, standalone project using EDP. Although secondary science preservice teachers in all cohort years created lesson plans that incorporated SEP, most of their projects utilized the science domain. For this study, the intervention common to all three cohort years, which was secondary science methods courses, included large group discussion with embedded explanations of possible future implementation of EDP as well as direct instruction with slideshow visuals defining and explaining EDP.

\subsection{Data Analysis}

Responses to the questionnaire provided data for qualitative analysis. Participant responses were typed into a spreadsheet and organized pre and post by year. Responses of yes, no, or maybe were tallied from the questionnaire. Data were separated by year and by pre-tests and post-tests. Coding of 
data into themes were first determined year-by-year and pre/post separately. Next, the themes and numbers of responses in those themes were compared to each other pre and post to look for changes from pre to post in a single year. Finally, the pre and post were combined to compare year-by-year across three years to determine changes over time.

Open-ended reasoning responses were categorized using a priori codes. The codes were developed based on open coding from in-service teacher responses and supported by the work of focus groups composed of professional engineers [27]. Codes were used a priori rather than creating new codes, as the researchers wished to replicate the earlier study with a different group of learners [27]. Also, the researchers tentatively predicted the participants held novice-level knowledge about engineering, given their lack of experience with engineering and teaching engineering. Because the codes from the earlier study were developed from experienced in-service teachers and supported by professional engineers, the researchers considered the codes pragmatically valid [27,35]. Table 2 displays the codes used.

Table 2. Modified code set for the components of engineering [27].

\begin{tabular}{ll}
\hline Code Set of Components of Engineering \\
\hline 1. Application/Real-world context \\
2. & Creating a product/design/model \\
3. & Experimentation \\
4. & Background research \\
5. & Revision process \\
6. & Challenge/multistep-problem \\
7. & Brainstorming \\
8. & Communication \\
\hline
\end{tabular}

The codes represent components of engineering and are not necessarily linear or hierarchal. Participants' if reasoning was deemed more informative than the eventual then yes, no, or maybe decision about whether the scenario was an example of EDP or teaching engineering. The components of engineering codes align with the NGSS SEP [1]. The unit of analysis was the shortest phrase that expressed a single idea. For example, "building" or "solving a problem" were both coded as creating a product/design/model. If the participant used and to join related ideas, the response was coded as a challenge/multistep-problem. For example, "If they use the chart to compare, or note cause effect, proportions, etc., it could be an engineering project" was coded as challenge/multistep-problem. The authors of this study independently coded the responses. Through discussion, the team came to agreement about the classification of data into the codes and emergent codes.

Additionally, a few important themes emerged. Constant comparison between the two researchers elevated these codes into emergent themes [39]. The researchers of this study agreed to specify the emergent themes pertaining to secondary science preservice teachers, namely teacher role and discipline-specific themes of reasoning. The emergent themes were not part of components of engineering and did not replicate the earlier study [27]. The emergent theme of teacher role has some relation to earlier work that analyzed responses in terms of both teacher and student roles in engineering [27]. In this study, responses indicated the teacher needed to play an active role in learning or guide learning, for example, "If the instructor actually explained the engineering of the park". The discipline-specific theme emerged based on student responses to why a scenario was or was not engineering. The responses were typically single-words such as "bioengineering" or short phrases such as "sounds more like chemistry to me" without further elaboration.

\section{Results}

The number of yes, no, and maybe responses were remarkably consistent over three cohort years. Figures 4-6 display the results from the pre-tests and post-tests for each of the three years. Not only did the responses change very little from pre- to post-test, but each year contains roughly the same 
distribution of responses-yes was answered most frequently, then maybe, then no was answered least frequently. The yes, no, and maybe responses are also consistent with each scenario pre- and post-test over the three cohort years. In other words, no specific scenario saw an appreciable change in yes, no, or maybe responses.

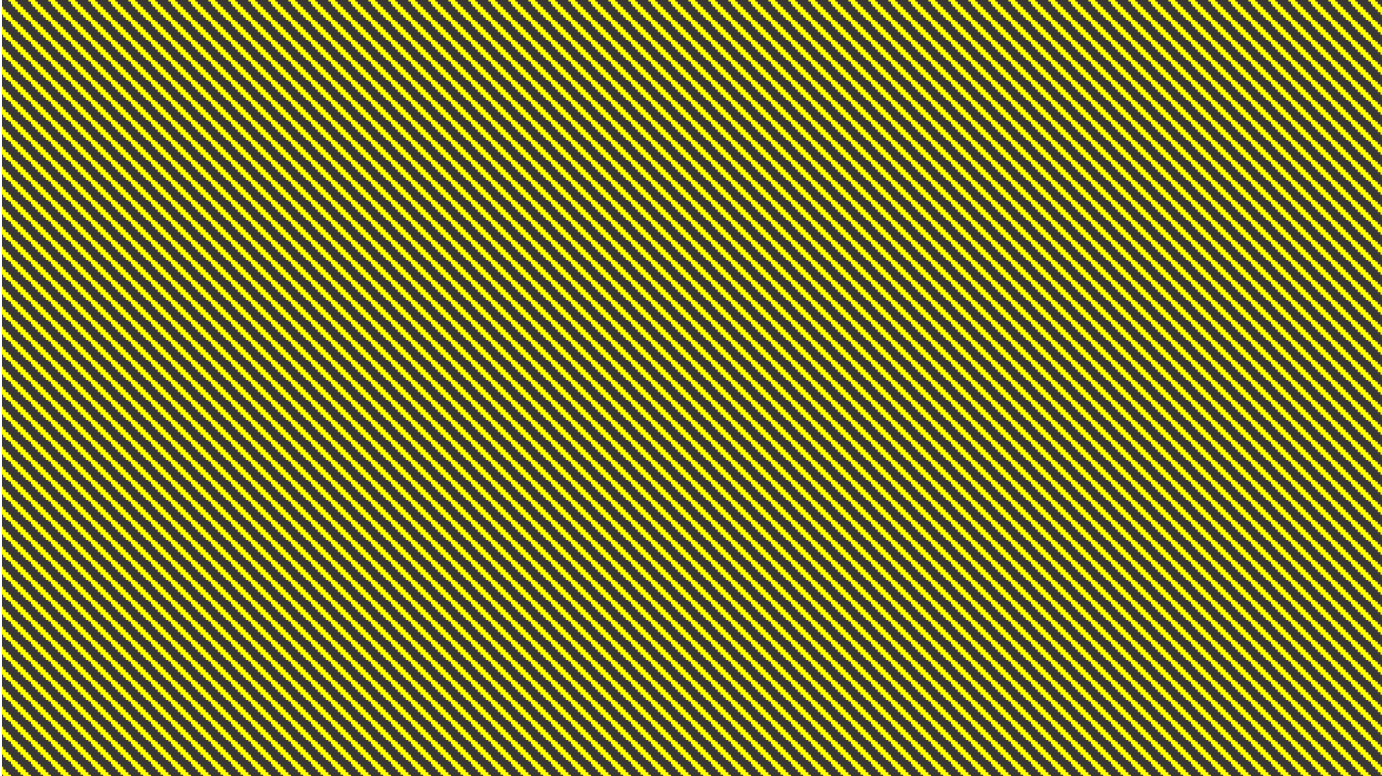

Figure 4. If answers (yes, no, and maybe) given for the scenarios, pre-test and post-test, 2015.

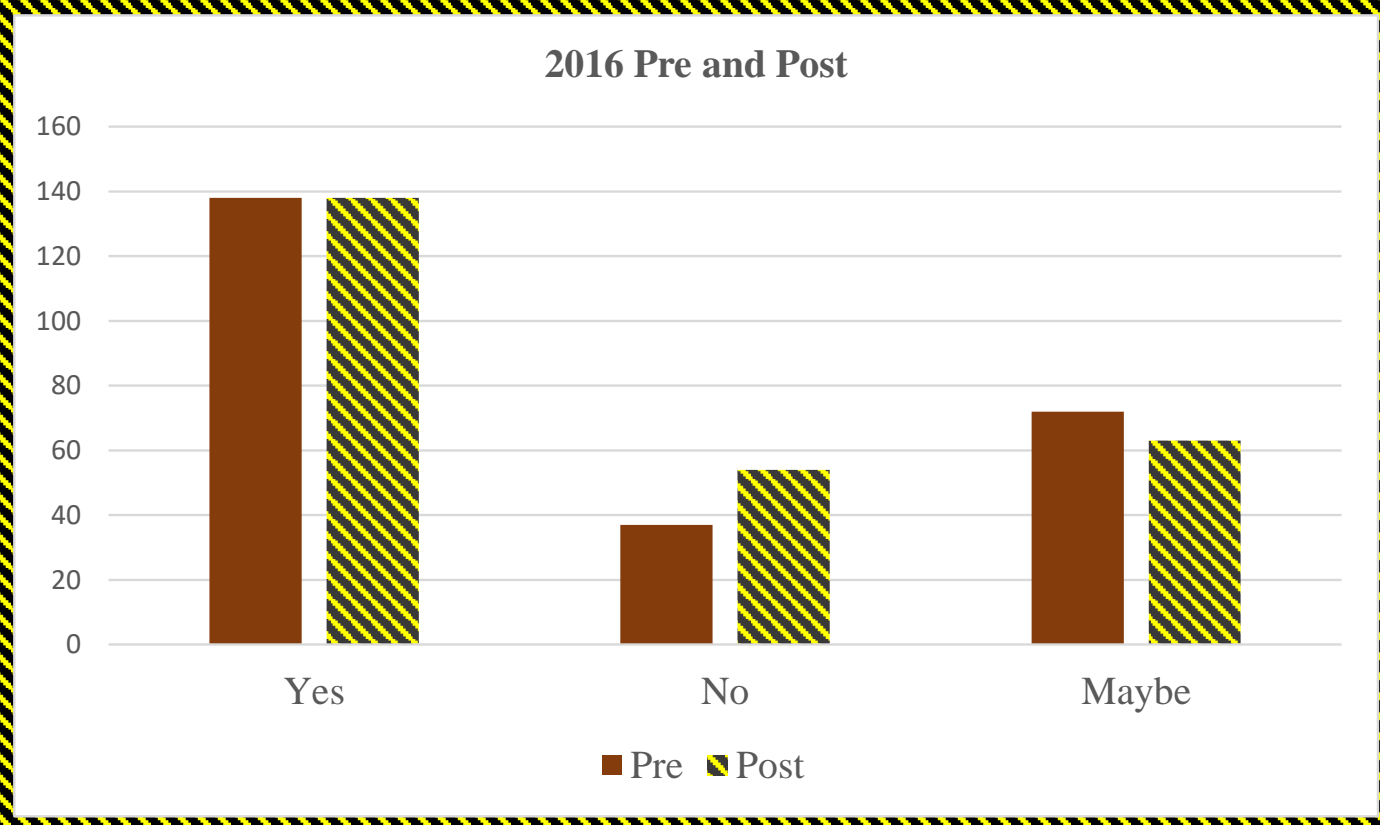

Figure 5. If answers (yes, no, and maybe) given for the scenarios, pre-test and post-test, 2016. 


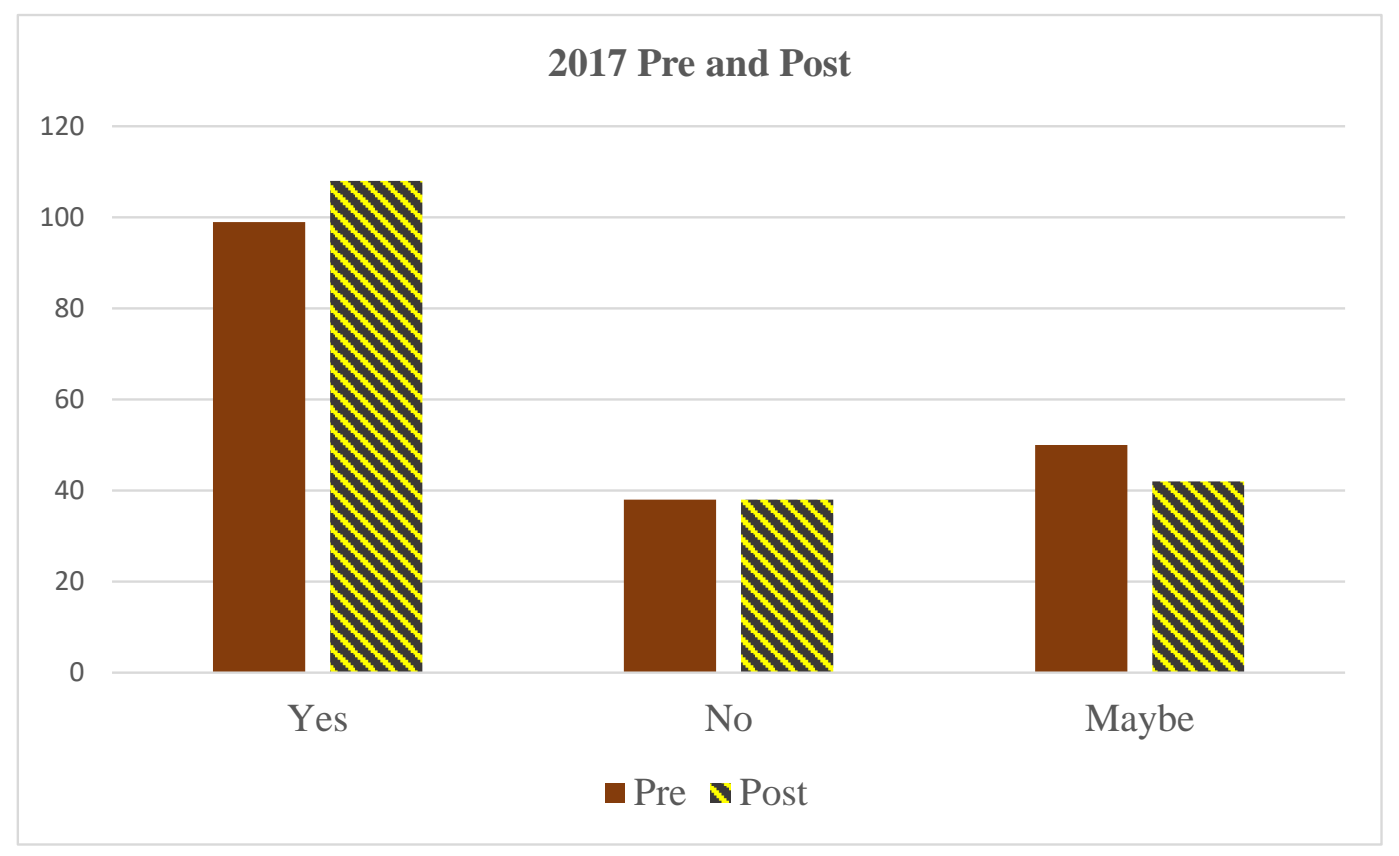

Figure 6. If answers (yes, no, and maybe) given for the scenarios, pre-test and post-test, 2017.

Open-ended reasoning responses were quantified by number of responses using reasoning that fit into one of the components of engineering or one of two emergent themes of reasoning. Overall, creating a product/design/model was the most often-used reasoning (554 total responses). The second most often-used reasoning was challenge/multistep-problem (312 total responses). The third most often-used reasoning was that engineering needed to have application/real-world context (260 total responses). Participants sometimes cited components such as revision process (90 total responses), background research (75 total responses), and brainstorming (42 total responses) as sufficient to be labeled engineering, although often tempered by the wish or constraint that these activities needed to produce something. Participants rarely used the components experimentation (28 total responses) and communication (19 total responses).

The authors created the aggregate trend column in Table 3 to showcase trends in responses from participants, pre- to post-test, over three cohort years. For example, the number of responses that used application/real-world context reasoning decreased from pre- to post-test in each year in all three years of the study. If there was no consistent trend from pre- to post-test in every year, no overall trend was reported.

The results showed a shift in reasoning from the pre-test to the post-test for certain reasonings. Creating a product/design/model increased from pre- to post-test over every cohort year and was also the reasoning with the highest total number of responses overall. Participants tended to cite application/real-world context, background research, and brainstorming as components sufficient to classify the activity as engineering less often after methods course completion. However, these decreases were offset by an increase in participants using the reasoning creating a product/design/model to solve a problem as a sufficient and necessary component of engineering. Figures 7-9 display the pre-test and post-test reasoning by cohort year. 
Table 3. Results of a priori themes and the number of responses, pre-test and post-test, by cohort year.

\begin{tabular}{|c|c|c|c|}
\hline Theme & Pre & Post & Pre/Post Cohort Trend \\
\hline \multirow{3}{*}{ Application/Real-world context } & $57(2015)$ & $44(2015)$ & \multirow{3}{*}{ Decrease } \\
\hline & $55(2016)$ & $43(2016)$ & \\
\hline & $16(2017)$ & 15 (2017) & \\
\hline \multirow{3}{*}{ Creating a product/design/model } & $83(2015)$ & $121(2015)$ & \multirow{3}{*}{ Increase } \\
\hline & $50(2016)$ & $126(2016)$ & \\
\hline & $43(2017)$ & $66(2017)$ & \\
\hline \multirow{3}{*}{ Experimentation } & $4(2015)$ & $4(2015)$ & \multirow{3}{*}{ No overall trend } \\
\hline & $2(2016)$ & $4(2016)$ & \\
\hline & 7 (2017) & $2(2017)$ & \\
\hline \multirow{3}{*}{ Background research } & $13(2015)$ & $7(2015)$ & \multirow{3}{*}{ Decrease } \\
\hline & $9(2016)$ & $9(2015)$ & \\
\hline & $21(2017)$ & $12(2017)$ & \\
\hline \multirow{3}{*}{ Revision process } & $24(2015)$ & $16(2015)$ & \multirow{3}{*}{ No overall trend } \\
\hline & $7(2016)$ & $8(2016)$ & \\
\hline & $7(2017)$ & $11(2017)$ & \\
\hline \multirow{3}{*}{ Challenge/multistep-problem } & $43(2015)$ & $45(2015)$ & \multirow{3}{*}{ No overall trend } \\
\hline & $53(2016)$ & $36(2016)$ & \\
\hline & $51(2017)$ & $59(2017)$ & \\
\hline \multirow{3}{*}{ Brainstorming } & $8(2015)$ & $5(2015)$ & \multirow{3}{*}{ Decrease } \\
\hline & 7 (2016) & $1(2016)$ & \\
\hline & $9(2017)$ & 7 (2017) & \\
\hline \multirow{3}{*}{ Communication } & $6(2015)$ & $2(2015)$ & \multirow{3}{*}{ No overall trend } \\
\hline & $0(2016)$ & $2(2016)$ & \\
\hline & $8(2017)$ & $1(2017)$ & \\
\hline
\end{tabular}

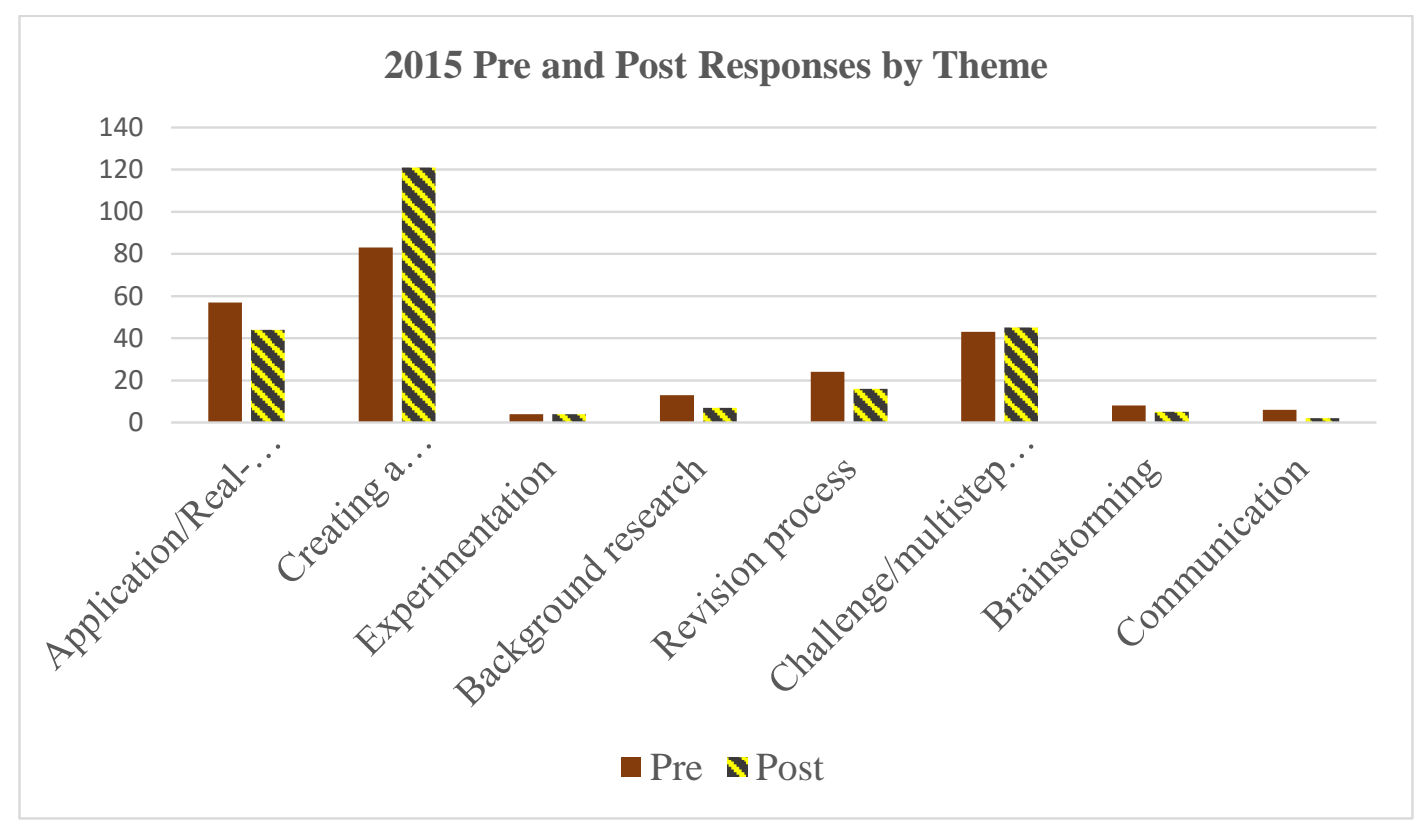

Figure 7. Pre-test and post-test results of the 2015 cohort. 


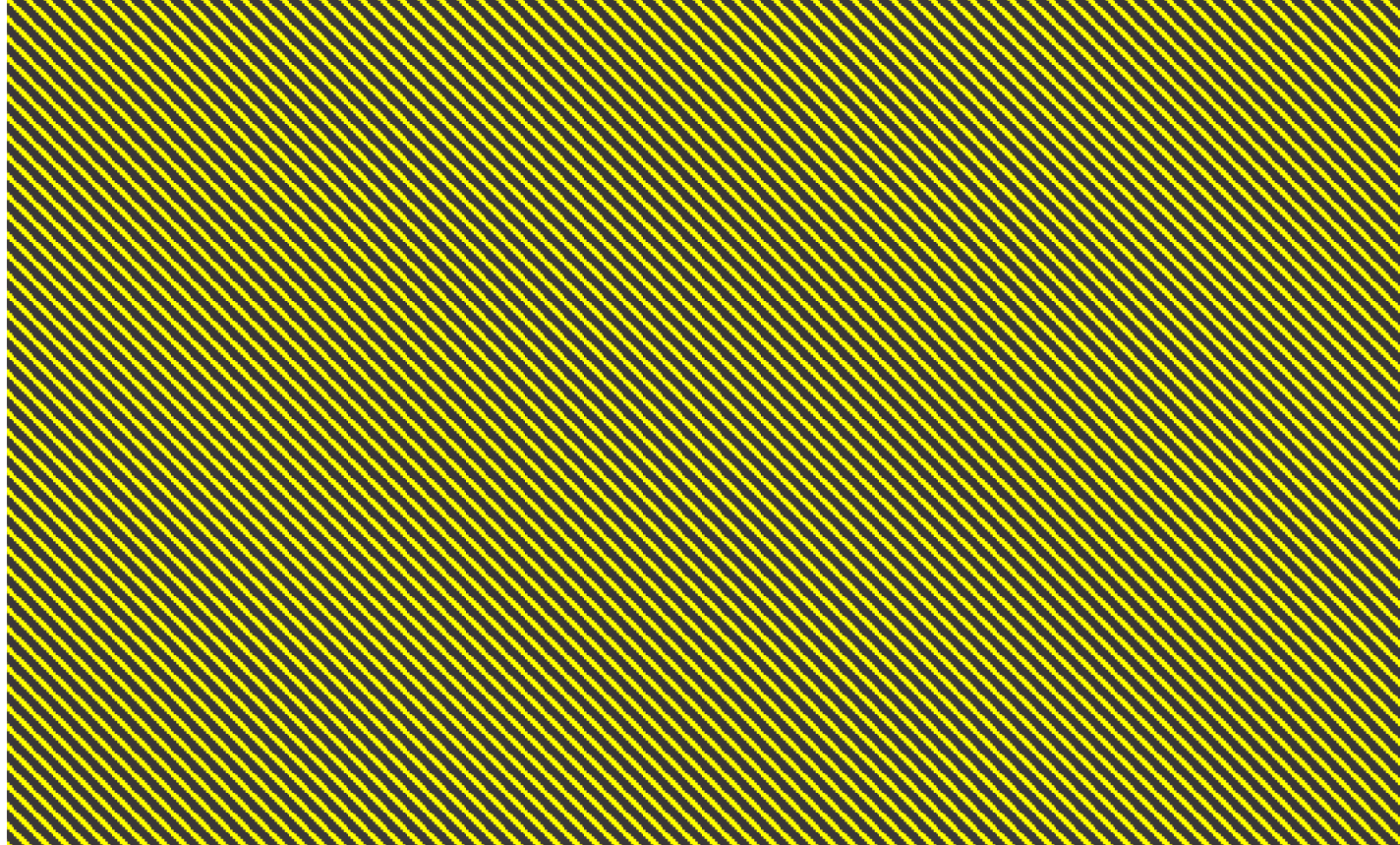

Figure 8. Pre-test and post-test of the 2016 cohort.

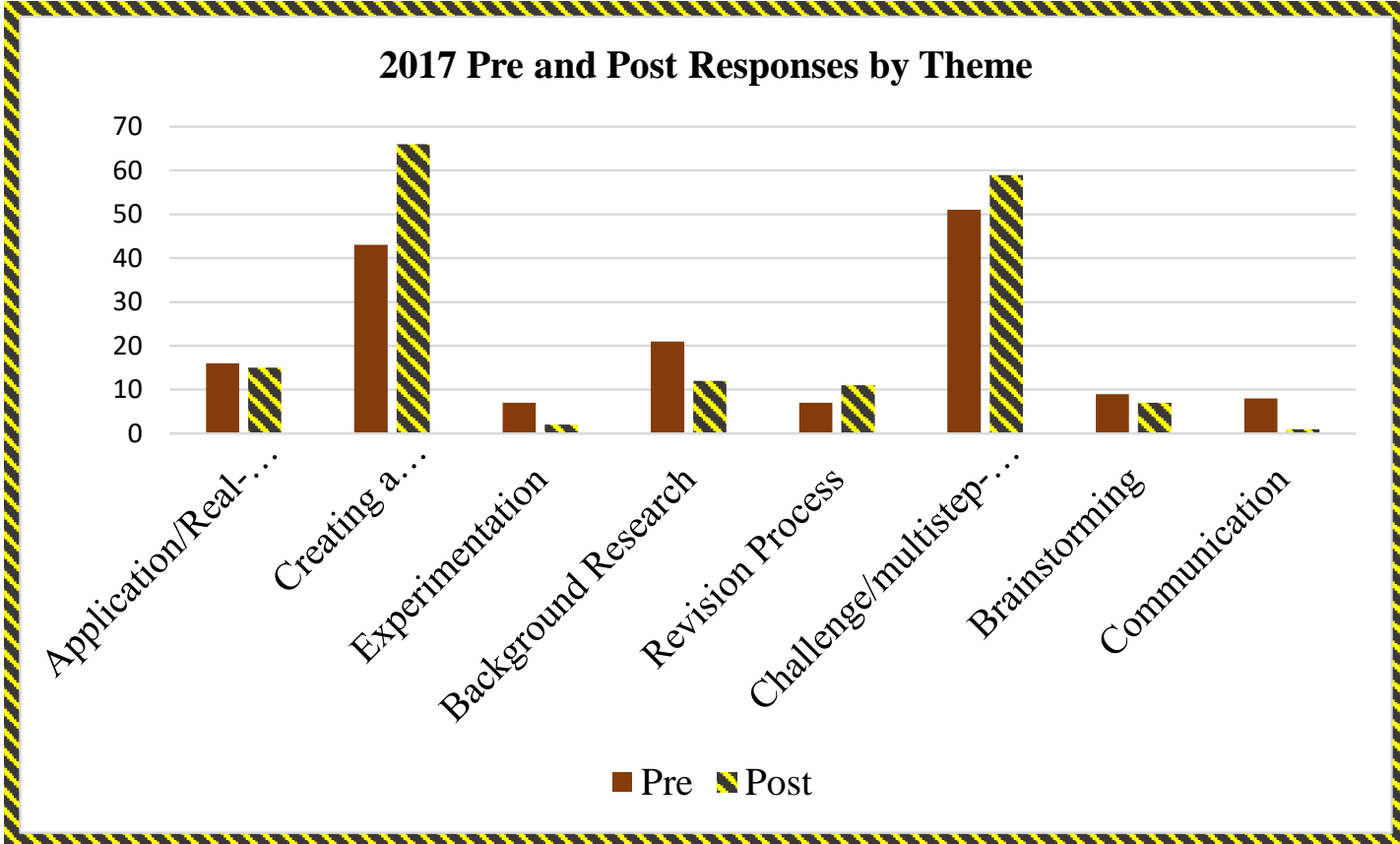

Figure 9. Pre-test and post-test of the 2017 cohort.

Given the high number of challenge/multistep-problem reasoning, participants seemed to perceive engineering as a multistep process that involves refining a best solution or design from several possibilities or iterations. Participants were satisfied that if the scenario called for a multistep process, especially if that process involved mathematical reasoning or solving equations, then it was engineering. Participants appeared to rationalize that although planning, data collection, and background research were an integral part of EDP, those components alone were not sufficient to call the activity engineering or an example of teaching engineering.

On the other hand, several participants across cohort years indicated that, in several scenarios, data analysis alone was sufficient for the activity to be considered engineering. There was no trend from pre- to post-test and no overall trend by cohort. As many participants described it, "Yes. Students 
must understand and interpret graphs" or "Yes. Analysis of data", represented a single necessary and sufficient component in terms of the scenario being classified as engineering. While some participants indicated that this step was one of many steps, others indicated that data analysis alone was considered sufficient to be classified as engineering.

Participants' reasoning was also examined in relation to the scenario questions, and a similar pattern of response to scenario was found consistently over time. One scenario, "A 4th grade class is doing a project on dinosaurs. A group of students makes a chart that compares the sizes of the five different dinosaurs showing their metric heights and weights" (1Q3) revealed that challenge/multistep-problem reasoning was used most often pre- to post-test in every cohort year. When participants changed their reasoning in the post-test, typically their responses changed to creating $a$ product/design/model, which is consistent with the overall increase of use of that reasoning. Table 4 displays the most often-used reasoning by scenario, pre- to post-test, for each cohort year. The changes from pre- to post-test are highlighted with bar shading.

Table 4. Most often-cited reason given for each scenario by cohort year. Note: The numbers in parenthesis refer to the components of engineering found in Table 2, and the grey bars indicate a change pre- to post-test.

\begin{tabular}{|c|c|c|}
\hline Scenario & Pre-test & Post-test \\
\hline \multirow{3}{*}{ 1Q1 } & 2015: Challenge (\#6) & 2015: Challenge (\#6) \\
\hline & 2016: Challenge (\#6) & 2016: Creating product (\#2) \\
\hline & 2017: Challenge (\#6) & 2017: Challenge (\#6) \\
\hline \multirow{3}{*}{ 1Q2 } & 2015: Challenge (\#6) & 2015: Challenge (\#6) \\
\hline & 2016: Challenge (\#6) & 2016: Creating product (\#2) \\
\hline & 2017: Challenge (\#6) & 2017: Challenge (\#6) \\
\hline \multirow{3}{*}{ 1Q3 } & 2015: Challenge (\#6) & 2015: Challenge (\#6) \\
\hline & 2016: Challenge (\#6) & 2016: Challenge (\#6) \\
\hline & 2017: Challenge (\#6) & 2017: Challenge (\#6) \\
\hline \multirow{3}{*}{ 1Q4 } & 2015: Creating product (\#2) & 2015: Creating product (\#2) \\
\hline & 2016: Application (\#1) & 2016: Application (\#1) \\
\hline & 2017: Challenge (\#6) & 2017: Challenge (\#6) \\
\hline \multirow{3}{*}{ 1Q5 } & 2015: Creating product (\#2) & 2015: Creating product (\#2) \\
\hline & 2016: Creating product (\#2) & 2016: Creating product (\#2) \\
\hline & 2017: Creating product (\#2) & 2017: Creating product (\#2) \\
\hline \multirow{3}{*}{ 1Q6 } & 2015: Challenge (\#6) & 2015: Challenge (\#6) \\
\hline & 2016: Challenge (\#6) & 2016: Creating product (\#2) \\
\hline & 2017: Challenge (\#6) & 2017: Challenge (\#6) \\
\hline \multirow{3}{*}{ 2Q1 } & 2015: Application (\#1) & 2015: Challenge (\#6) \\
\hline & 2016: Challenge (\#6) & 2016: Creating product (\#2) \\
\hline & 2017: Challenge (\#6) & 2017: Challenge (\#6) \\
\hline \multirow{3}{*}{ 2Q2 } & 2015: Challenge (\#6) & 2015: Creating product (\#2) \\
\hline & 2016: Creating product (\#2) & 2016: Creating product (\#2) \\
\hline & 2017: Challenge (\#6) & 2017: Revision process (\#5) \\
\hline \multirow{3}{*}{ 2Q3 } & 2015: Background research (\#4) & 2015: Background research (\#4) \\
\hline & 2016: Challenge (\#6) & 2016: Creating product (\#2) \\
\hline & 2017: Background research (\#4) & 2017: Challenge (\#6) \\
\hline \multirow{3}{*}{ 2Q4 } & 2015: Creating product (\#2) & 2015: Creating product (\#2) \\
\hline & 2016: Creating product (\#2) & 2016: Creating product (\#2) \\
\hline & 2017: Creating product $(\# 2)$ & 2017: Creating product (\#2) \\
\hline \multirow{3}{*}{ 2Q5 } & 2015: Creating product (\#2) & 2015: Creating product (\#2) \\
\hline & 2016: Creating product (\#2) & 2016: Creating product (\#2) \\
\hline & 2017: Creating product (\#2) & 2017: Creating product (\#2) \\
\hline
\end{tabular}


Table 4. Cont.

\begin{tabular}{lll}
\hline Scenario & Pre-test & Post-test \\
& 2015: Creating product (\#2) & 2015: Creating product (\#2) \\
\multirow{2}{*}{ QQ6 } & 2016: Application (\#1) & 2016: Creating product (\#2) \\
& 2017: Creating product (\#2) & 2017: Creating product (\#2) \\
\hline \multirow{3}{*}{ QQ7 } & 2015: Creating product (\#2) & 2015: Creating product (\#2) \\
& 2016: Creating product (\#2) & 2016: Creating product (\#2) \\
& 2017: Creating product (\#2) & 2017: Creating product (\#2) \\
\hline \multirow{3}{*}{ 2Q8 } & 2015: Application (\#1) & 2015: Creating product (\#2) \\
& 2016: Challenge (\#6) & 2016: Creating product (\#2) \\
& 2017: Communication (\#8) & 2017: Creating product (\#2) \\
\hline \multirow{3}{*}{ 2Q9 } & 2015: Creating product (\#2) & 2015: Application (\#1) \\
& 2016: Challenge (\#6) & 2016: Creating product (\#2) \\
& 2017: Challenge (\#6) & 2017: Creating product (\#2) \\
\hline \multirow{3}{*}{ 2Q10 } & 2015: Teacher role (no \#) & 2015: Creating product (\#2) \\
& 2016: Application (\#1) & 2016: Application (\#1) \\
& 2017: Teacher role (no \#) & 2017: Teacher role (no \#) \\
\hline \multirow{3}{*}{ 2Q11 } & 2015: Revision process (\#5) & 2015: Revision process (\#5) \\
& 2016: Revision process (\#5) & 2016: Creating product (\#2) \\
& 2017: Revision process (\#5) & 2017: Revision process (\#5) \\
\hline
\end{tabular}

Overall, when reasoning changed, it changed to creating a product/design/model. However, this happened only in some scenarios; for example, in the debate on the pros and cons of genetically modified food (2Q8). Other scenarios gathered remarkably consistent reasoning, such as students building a compressed air rocket from a kit (2Q5) and students building a scale model of the solar system (1Q5). Participants gave consistent reasoning in scenarios that used words common in engineering, such as scale, model, and rocket.

Several participants in all three cohort years changed their reasoning in two scenarios. The two scenarios were the debate about the pros and cons of genetically modified foods (2Q8) and the math teacher who had students measure dripping water and then create a linear equation of the data (2Q9). For the genetically modified food debate, several participants in all three cohort years used creating a product/solution/model reasoning in the post-test. Reasoning included, "Not problem solving", and "They are not designing a solution to a need or problem" which is interesting to consider that the participant did not use communication reasoning as offering a solution to a problem. For the data collection and graphing of a dripping faucet, pre-test reasoning was that the scenario was too simplistic, "No, just graphing", while the reasoning on the post-test used phrases such as "No problem no product".

Several participants in two of the three years changed their reasoning in three scenarios. The three scenarios included two students working on an assigned slope y-intercept problem for homework from their textbook (2Q1), a student making fudge (2Q2), and a student at home watching a TV documentary about the building of the Hoover Dam in the 1930s (2Q3). While the slope y-intercept problem remained primarily "no", the reasoning changed from that it had no real-world application to that it did not create a product to solve a problem. The reasoning that it was too simple and did not offer a challenge/multistep-problem was used in both years. For the scenario of a student making fudge, there was an increase in reasoning that the activity could employ EDP to create or improve the product. This was in contrast to the pre-test, in which some participants viewed the activity as "cooking". Some participants changed their reasoning about the student watching the Hoover Dam documentary scenario, but in both the pre-test and post-test, the reasoning revolved around the activity as the students "not doing anything" or "No problem and no product". 


\section{Emergent Reasoning Themes of Secondary Science Preservice Teachers}

A line of reasoning emerged during data analysis as that of the teacher role. Two reasoning themes that emerged in this study are displayed in Table 5. Several participants indicated that the teacher needed to emphasize the application to the real-world or guide students' thinking, for example, "Maybe. If the instructor can relate the rollercoaster design" and "Maybe. How does the teacher encourage their kids to think about the engineering/design process?" and "Maybe. As long as the teacher doesn't handle everything or make cookie-cutter plans". Others reasoned that a teacher needed to actively ensure learning, such as, "Maybe. If teaching actually occurs". Participants used the teacher role reasoning somewhat often (31 total responses) and most often as a response to one scenario, a class trip to an amusement park (2Q9). Use of the teacher role theme showed no overall trend over time.

Table 5. Emergent themes pre-test and post-test across cohort groups 2015-2017.

\begin{tabular}{cccc}
\hline Emergent Reasoning Theme & Pre & Post & Pre/Post and Cohort Year Aggregate Trend \\
\hline \multirow{2}{*}{ Teacher role } & $4(2015)$ & $4(2015)$ & \\
& $0(2016)$ & $3(2016)$ & No overall trend \\
& $13(2017)$ & $4(2017)$ & \\
Discipline-specific & $28(2015)$ & $11(2015)$ & Decrease \\
& $12(2016)$ & $4(2016)$ & \\
& $3(2017)$ & $4(2017)$ & \\
\hline
\end{tabular}

Another emergent theme of reasoning was discipline-specific connections, indicated by stating a particular discipline as reasoning with little further elaboration. As with the teacher role reasoning theme, a connection to other disciplines was not considered a component of engineering but rather a theme of reasoning why a scenario was or was not engineering. Some examples were, "No. Because fudge is more chemistry based than engineering", or "Yes. Focused in Civil Engineering", or "physics is taught here". This reasoning occurred moderately often compared to other responses (72 total responses) in every scenario with no strong correspondence to any scenario in particular. Use of this reasoning decreased from pre-test to post-test for every cohort year. For example, simple rationale such as, "Civil engineering" or "Bioengineering" decreased pre- to post-test and was often replaced by more descriptive reasoning, such as, "Yes. They have to make observations, measure, are creating something" for the scenario of a student making fudge.

Several participants, as rationale for their decision to categorize the activity as not engineering, claimed it "sounds more like chemistry" or "No, Cooking is hardly engineering". This represents novice understanding, where participants viewed academic disciplines as rigid and well-defined. As mentioned previously, such reasoning was more common in the pre-tests. The participants failed to see applications of other disciplines as pertinent to engineering. Most of the time these missed applications were other STEM disciplines, although one participant indicated that the debate about the pros and cons of genetically modified foods sounded, "more agricultural and social-political". The domain of mathematics was cited in various scenarios as rationale for considering the scenario engineering, "Maybe. If we discuss math behind this" and as rationale for considering the scenario as not engineering, "No. No math". Although several participants wrote that mathematics was necessary component of engineering, others indicated that it was part of background research, a skill building component, or that it needed to have multiple, complex steps and/or solutions and not just "plug and chug".

\section{Discussion}

This study builds on earlier work by replicating among preservice teachers many of the themes identified by in-service teachers in another study. The in-service teachers gave similar reasoning for required components of engineering or teaching engineering [27]. In-service teachers described 
Application/Real-world context, creating a product/design/model, and challenge/multistep-problem most often as necessary components of engineering [27]. In this study, secondary science preservice teachers described the same three themes most often, although the exact ranking differed, most likely due to the difference in participants between that study $(n=16)$ and this one $(n=43)$. In light of the consistent results, the authors of this work believe that this study establishes replicability and pragmatic validity of the instrument.

The important themes of reasoning that emerged, namely teacher role and discipline-specific, pertain to the novice stage at which participants conceptualized engineering and teaching engineering and how those conceptions changed after instruction. This was most evident in the pre- to post-test change in discipline-specific reasoning. If science educators ask preservice teachers to integrate SEP into science lessons, then, the preservice teachers need to recognize that science, technology, engineering, and mathematics (STEM) disciplines are not mutually exclusive, and science educators must explicitly deliver this instruction. A model of integrated STEM courses has been proposed, which aligns with the NGSS [13]. Making explicit connections between disciplines and the integration of EDP into various science and mathematics domains may help move teachers from novice to expert levels [23,30]. A focus on the integration of STEM including activities such as lesson plans that encourage secondary science preservice teachers to integrate EDP into SEP may also be helpful.

Moving past a narrowly-defined concept of the boundaries of academic disciplines (or silos) is necessary if secondary science teachers aim to raise awareness of engineering careers in their students. One of the outcomes of an engineering PD for in-service teachers was fostering an awareness of engineering as a possible future career for their students [32], and this type of explicit instruction is beneficial and necessary. If secondary science teachers plan to instill an understanding of engineering in their student populations, then, they need to recognize that engineering is integrated among many STEM disciplines and moreover, that many STEM disciplines incorporate aspects of the engineering design process into discipline-specific practices. The fact that participants decreased the use of discipline-specific justifications as sufficient to exclude the scenario from engineering from pre- to post-test shows that participants may have recognized these cognitive contradictions and thought through how to resolve the issues [30]. Therefore, secondary science teachers could raise awareness of engineering careers in their classrooms by incorporating a more integrated, multidisciplinary, collaborative epistemological perspective of the engineering domain.

Many secondary science preservice teachers have an emerging understanding of the role the teacher should play in learning, particularly EDP. The responses that fit the teacher role theme used third-person rather than first-person. On the basis of textural analysis of the responses, the authors think use of this reasoning indicates an emerging perception of effective teaching in a general sense, not specific to teaching engineering domain. Because no participant indicated actual classroom teaching experience, no one drew a response from previous experience. Participants' teacher role responses may reflect emerging ideas about the role of the teacher in learning and the impact of student-centered learning. Secondary science preservice teachers' concepts of how teachers influence learning may need authentic experience to fully crystallize.

A novice level of understanding also became apparent by the number of responses that cited an over-simplified short phrase representing the creating a product/design/model theme as a component of engineering. This 'product for a problem' theme represented the most-often cited reason for categorizing the activity as engineering and was also the only theme that increased from pre-test to post-test in every cohort year. Novice knowledge does not entail the rich, multiple connections with other knowledge domains that is characteristic of expert knowledge [30]. Moreover, novices are less able to recognize subtle but important patterns and the significance of those patterns [23,30]. By applying an oversimplified, easy-to-remember phrase to many scenarios, participants revealed their inexperience with nuances and considerations that each scenario brings to bear. It is noteworthy to add that the science educator might have proliferated this participant response by repeating the phrase during the science methods coursework. 
During the secondary science methods course discussion of EDP, providing a definition of engineering, and planning and implementing EDP in SEP, the science educator mentioned that engineering was a solution to a problem, provided a benefit to society, or was a process leading to a product realized by creating or building something. Many secondary science preservice teachers condensed these discussion points down to soundbite-size definitions that varied by cohort year. They tended to repeat the short phrase definition for almost all of the scenarios offered in the post-test. Almost all of the phrases dealt with a product, solution, or model. For example, a few phrases were: "Solving a problem", "Not creating anything", "No. No problem, no product", and "Starts with a problem, ends with a product". This style of reasoning most likely accounts for the slight drops in other components of engineering, namely background research, brainstorming, and communication, and the increase of defining engineering as creating a product/design/model. As participants internalized a new definition, in this case classification of the engineering domain, they tended to oversimplify and overgeneralize [23]. Hence, science educators should take caution and speak explicitly about what belongs in science and engineering practices.

Although the results represent progress in the sense that secondary science preservice teachers refined their epistemological knowledge of the EDP domain, opportunities exist for developing misconceptions. In recognizing that EDP involves creating of a model, product, or solving a problem, participants may have progressed from novice to "competent beginners" [23] (p. 37). Yet there is a danger for misconceptions to form. As mentioned previously, researchers in a prior study identified four misconceptions about engineering: (a) that research methods are defined by long-term implications or outcomes, (b) that science and engineering is hierarchal, (c) that creativity is appropriate only in the design/planning phase, and (d) that an engineering process cannot be a research outcome [24]. Any of those misconceptions could arise from early-career teachers simply applying the basic short phrase definition when planning future classroom curriculum.

\subsection{Limitations}

A limitation to this study is that although the results are compared to the themes generated in an earlier study, the methods of collecting data differed. Researchers in the earlier study collected data by verbal interview, which provided an opportunity to clarify questions, ask for clarification in responses, or ask follow-up questions [27]. A limitation of the written questionnaire is the inability to follow-up to the participants' responses. On the other hand, participants were free to expand on their reasoning and in fact, prompted to do so, limited only by how much they chose to write. One advantage of a written questionnaire is the reduction of interviewer bias and greater participant confidentiality. In this study, participants completed the questionnaires individually, and did not discuss their answers with their peers during questionnaire administration, which might have led to more honest answers. Participants were assured confidentiality to perhaps a greater extent than they would in-person interviews due to reaction of the interviewer, nonverbal language, prior acquaintance, etc. Participants were also assured of confidentiality because they generated a four-digit code for the pre- and post-questionnaires. They did not use their names anywhere other than the separate consent form.

This study was also limited by the learner context. Because all of the participants attended the same university and moved through the same secondary teacher education program over three years, the learner context did not appreciably differ by cohort year. While this encouraged reduction of variables, it also limited generalizability and multiple perspectives. Another limitation is that the researchers did not ask how many engineering courses participants had taken. It is not a requirement at the university where the study took place for students pursuing a secondary science education degree to take engineering courses. Other than the sole engineering major, it is unlikely that any of the participants had taken courses in engineering content.

This study used a subjectivist lens to describe individuals' beliefs and perspectives about a knowledge domain. In light of the modest cohort size $(n=43)$, no practical significance from year to year, and qualitative methodology the study is not generalizable to a larger population. The overall 
qualitative research framework using an interpretivist, constructivism theoretical perspective does not lend itself to quantitative analysis of the yes, no, and maybe questionnaire responses [35]. General trends were described to find practical significance [35]. Readers might find pragmatic validity to this study by determining if the results apply to other learners in other contexts.

\subsection{Recommendations}

From an instructional design vantage point, this study indicates a need for instruction. There is a clear need for this type of instruction if secondary science preservice teachers are providing novice-level reasoning as rationale for their answers to the scenario questions [5]. For example, several participants began with narrowly defined views of discipline areas, such as civil engineering or biology. Those participants did not view engineering as multidisciplinary endeavor, or, alternatively, that other disciplines could integrate engineering. Although evidence of this reasoning decreased from pre- to post-test, it still indicates novice conceptualizations need to be explored in greater detail in early-career PD or incorporated into redesign of secondary science methods courses.

This study indicates that science educators of secondary science preservice methods courses should begin instruction from a point of novice student understanding. Standard learner analysis parameters in instructional design include prior beliefs, knowledge, and experience [5]. With baseline information provided by this study, namely that instruction does impact beliefs about the EDP domain, effective instruction may be designed that can assist teachers adopt an innovation of integrating EDP in the classroom. Additionally, instructional efforts should be directed at preventing misconceptions, examining each component of EDP, and integrating EDP into SEP as well as with other STEM disciplines.

Examining each component of EDP should include examining the component of data analysis. Authentic science projects emphasizing how components of EDP fit together may help further participant understanding [18]. Secondary science preservice teachers' perception that data analysis alone is sufficient for classification as engineering presents an area for further research. Some researchers have begun to address this issue through expanded lessons focusing on data interpretation as evidence [22]. There is a need for methods instruction that encourages secondary science preservice teachers to expand their epistemological knowledge about engineering and the role data analysis plays as one necessary, but not entirely sufficient, part of EDP.

\section{Conclusions}

This study contributed to an instructional design needs and learner analysis by describing perceptions of engineering and teaching engineering among secondary science preservice teachers. Specifically, the authors described participant perceptions of which engineering components were required to classify an activity as engineering. As stated earlier, participants can be analyzed by a description of changing learner characteristics [5]. Although yes, no, or maybe responses did not appreciably change from pre- to post-test in any year, participants' reasoning did appreciably change after methods courses instruction in all three cohort years. This indicates that instruction is an effective way to shape perceptions and epistemological beliefs about engineering and teaching engineering [5]. Thus, this study supports a need for instruction on an innovation, illustrated in Figure 2-knowledge can be taught, and perceptions can change, about an innovation.

While it is encouraging to see that cognitive shifts in thinking occurred after instruction intervention, this study also comes with a warning of the dangers of oversimplification. Participants gained an emergent understanding of engineering and teaching engineering after methods course intervention. During instruction, many secondary science preservice teachers absorbed a working definition of engineering that shortened to some version of a process leading to the creation of a product or solving a problem. Although these soundbite-size definitions helped many to conceptualize engineering in a more holistic way, opportunities exist for misconceptions to arise following a too-narrow definition. Caution should be taken to ensure that the opportunity to acquire these 
misconceptions is minimized. Recommendations for designers of secondary science methods courses and early-career PD include providing opportunities for teachers to refine their perceptions and deepen their understanding about engineering and teaching engineering. Ways this may be addressed include examining the role of data analysis in SEP and exploring how EDP may be integrated with other STEM disciplines.

Author Contributions: Conceptualization, A.C.B.; Data curation, T.J.K. and A.C.B.; Formal analysis, T.J.K.; Funding acquisition, A.C.B.; Investigation, A.C.B.; Methodology, T.J.K.; Project administration, A.C.B.; Supervision, A.C.B.; Validation, T.J.K. and A.C.B.; Writing—original draft, T.J.K.; Writing—revisions \& editing, A.C.B.

Funding: This work was supported by a National Science Foundation Noyce grant [\#1339853]. Any opinions, findings, conclusions, or recommendations expressed in this material are those of the authors and do not necessarily reflect the views of the National Science Foundation.

Conflicts of Interest: The authors declare no conflict of interest.

\section{References}

1. NGSS Lead States. Next Generation Science Standards: For States, by States; The National Academies Press: Washington, DC, USA, 2013.

2. Rogers, E.M. Diffusion of Innovations, 5th ed.; Free Press: New York, NY, USA, 2003; ISBN 978-0-7432-2209-9.

3. Vincenti, W.G. What Engineers Know and How They Know It: Analytical Studies from Aeronautical History; The Johns Hopkins University Press: Baltimore, MD, USA, 1990; ISBN 0-8018-4588-2.

4. French, D.A.; Burrows, A.C. Evidence of science and engineering practices in preservice secondary science teachers' instructional planning. J. Sci. Educ. Technol. 2018. [CrossRef]

5. Smith, P.L.; Ragan, T.J. Instructional Design, 3rd ed.; John Wiley \& Sons, Inc.: Hoboken, NJ, USA, 2005; ISBN 0-471-39353-3.

6. American Association for the Advancement of Science (AAAS). Project 2061: Science for All Americans; Oxford University Press: New York, NY, USA, 1990.

7. Moore, T.J.; Tank, K.M.; Glancy, A.W.; Kersten, J.A. NGSS and the landscape of engineering in K-12 state science standards. J. Res. Sci. Teach. 2015, 52, 296-318. [CrossRef]

8. Locke, E. Proposed model for a streamlined, cohesive, and optimized K-12 STEM curriculum with a focus on engineering. J. Technol. Stud. 2009, 35, 23-35. [CrossRef]

9. Carr, R.L.; Bennett, I.V.L.D.; Strobel, J. Engineering in the K-12 STEM standards of the 50 U.S. states: An analysis of presence and extent. J. Eng. Educ. 2012, 101, 539-564. [CrossRef]

10. Pleasants, J.; Olson, J.K. What is engineering? Elaborating the nature of engineering for K-12 education. Sci. Educ. 2018, 1-22. [CrossRef]

11. Wyoming State Board of Education. 2016 State Standards. Available online: https:/ / edu.wyoming.gov/ educators/standards/science (accessed on 10 November 2018).

12. Katehi, L.; Pearson, G.; Feder, M. Engineering in K-12 Education: Understanding the Status and Improving the Prospects; National Academies Press: Washington, DC, USA, 2009.

13. Burrows, A.; Slater, T. A proposed integrated STEM framework for contemporary teacher preparation. Teach. Educ. Pract. 2015, 28, 318-330.

14. Ebert-May, D.; Derting, T.L.; Hodder, J.; Momsen, J.L.; Long, T.M.; Jardeleza, S.E. What we say is not what we do: Effective evaluation of faculty professional development programs. Bioscience 2011, 61, 550-558. [CrossRef]

15. Daugherty, J.L.; Custer, R.L. Secondary level engineering professional development: Content, pedagogy, and challenges. Int. J. Technol. Educ. 2012, 22, 51-64. [CrossRef]

16. Burrows, A. Partnerships: A systemic study of two professional developments with university faculty and K-12 teachers of science, technology, engineering, and mathematics. Probl. Educ. 21st Century 2015, 65, 28-38.

17. Burrows, A.; Borowczcak, M.; Slater, T.; Haynes, J. Teaching computer science \& engineering through robotics: Science \& art form. Probl. Educ. 21st Century 2012, 47, 6-15.

18. Burrows, A.C.; DiPompeo, M.; Myers, A.; Hickox, R.; Borowczak, M.; French, D.; Schwortz, A. Authentic science experiences: Pre-collegiate science teachers' successes and challenges during professional development. Probl. Educ. 21st Century 2016, 70, 59-73. 
19. Hofer, B.K.; Pintrich, P.R. The development of epistemological theories: Beliefs about knowledge and knowing and their relation to learning. Rev. Educ. Res. 1997, 67, 88-140. [CrossRef]

20. Gagné, R.M.; Briggs, L.J.; Wager, W.W. Principles of Instructional Design, 4th ed.; Harcourt Brace Jovanovich College Publishers: Fort Worth, TX, USA, 1992; ISBN 0-03-034757-2.

21. Antink-Meyer, A.; Brown, R.A. Second-career science teachers' classroom conceptions of science and engineering practices examined through the lens of their professional histories. Int. J. Sci. Educ. 2017, 39, 1511-1528. [CrossRef]

22. Duncan, R.G.; Chinn, C.A.; Brazilai, S. Grasp of evidence: Problematizing and expanding the next generation science standards' conceptualization of evidence. J. Res. Sci. Teach. 2018, 55, 907-937. [CrossRef]

23. National Research Council. How People Learn: Brain, Mind, Experience, and School; National Academy Press: Washington, DC, USA, 2000.

24. Antink-Meyer, A.; Meyer, D.Z. Science teachers' misconceptions in science and engineering distinctions: Reflections on modern research examples. J. Sci. Teach. Educ. 2016, 27, 625-647. [CrossRef]

25. Jones, M.G.; Carter, G. Science teacher attitudes and beliefs. In Handbook of Research on Science Education; Abell, S.K., Lederman, N.G., Eds.; Routledge: New York, NY, USA, 2007.

26. Hewson, P.W.; Hewson, M.G.A.B. Analysis and use of a task for identifying conceptions of teaching science. J. Educ. Teach. 1989, 15, 191-209. [CrossRef]

27. Thatcher, W.; Meyer, H. Identifying initial conceptions of engineering and teaching engineering. Educ. Sci. 2017, 7, 88. [CrossRef]

28. Yasar, S.; Baker, D.; Robinson-Kurpius, S.; Krause, S.; Roberts, C. Development of a survey to assess $\mathrm{K}-12$ teachers' perceptions of engineers and familiarity with teaching design, engineering, and technology. J. Eng. Educ. 2006, 95, 205-216. [CrossRef]

29. Tank, K.M.; Raman, D.R.; Lamm, M.H.; Sundararajan, S.; Estapa, A. Teaching educators about engineering. Sci. Child. 2017, 55, 74-79. [CrossRef]

30. Ambrose, S.A.; Bridges, M.W.; DiPietro, M.; Lovett, M.C.; Norman, M.K. How Learning Works: Seven Research-Based Principles for Smart Teaching; John Wiley \& Sons: San Francisco, FL, USA, 2010; ISBN 978-0-470-48410-4.

31. Nathan, M.J.; Tran, N.A.; Atwood, A.K.; Prevost, A.; Phelps, A. Beliefs and expectations about engineering preparation exhibited by high school STEM teachers. J. Eng. Educ. 2010, 99, 409-426. [CrossRef]

32. Autenrieth, R.L.; Lewis, C.W.; Butler-Purry, K.L. Long-Term impact of the enrichment experiences in engineering $\left(\mathrm{E}^{3}\right)$ summer teacher program. J. STEM Educ. 2017, 18, 25-31.

33. Hammack, R.; Ivey, T.A.; Utley, J.; High, K.A. Effect of an engineering camp on students' perceptions of engineering and technology. J. Pre-College Eng. Educ. Res. 2015, 5. [CrossRef]

34. Cunningham, C.M.; Lachapelle, C.; Lindgren-Streicher, A. Assessing elementary school students' conceptions of engineering and technology. In Proceedings of the 2005 American Society for Engineering Education Annual Conference \& Exposition, Portland, OR, USA, 12-15 June 2005; Available online: https: / / peer.asee. org/14836 (accessed on 26 December 2018).

35. Koro-Ljungberg, M.; Yendol-Hoppey, D.; Smith, J.J.; Hayes, S.B. (E)pistemological awareness, instantiation of methods, and uninformed methodological ambiguity in qualitative research projects. Educ. Res. 2009, 38, 687-699. [CrossRef]

36. Branch, R.M.; Dousay, T.A. Survey of Instructional Design Models, 5th ed.; AECT: Bloomington, IN, USA, 2015; ISBN 9780997075502.

37. Council of Chief State School Officers. Interstate Teacher Assessment and Support Consortium InTASC Model Core Teaching Standards and Learning Progressions for Teachers 1.0: A Resource for Ongoing Teacher Development; CCSSO: Washington, DC, USA, 2013.

38. NSTA. Standards for Science Teacher Preparation. Available online: http://www.nsta.org/preservice/docs/ 2012NSTAPreserviceScienceStandards.pdf (accessed on 10 November 2018).

39. Merriam, S.B.; Tisdell, E.J. Qualitative Research: A Guide to Design and Implementation, 4th ed.; Jossey-Bass: San Francisco, CA, USA, 2016; ISBN 978-1-119-00361-8.

(C) 2019 by the authors. Licensee MDPI, Basel, Switzerland. This article is an open access article distributed under the terms and conditions of the Creative Commons Attribution (CC BY) license (http:// creativecommons.org/licenses/by/4.0/). 